Published as: Reddy, S.M. \& Potts, G.J. 1999. Constraining absolute deformation ages: The relationship between deformation mechanisms and isotope systematics. Journal of Structural Geology, 21, 1255-1265.

\title{
Constraining Absolute Deformation Ages: The Relationship between Deformation Mechanisms and Isotope Systematics
}

\author{
Steven M. Reddy \\ Tectonics Special Research Centre, School of Applied Geology, Curtin University of \\ Technology, Perth, WA 6102, Australia.

\section{Graham J. Potts} \\ Department of Earth Sciences, University of Liverpool, Liverpool, L69 3BX, U.K.
}

\begin{abstract}
Isotope diffusion in a mineral is strongly temperature dependent but is also a function of grain size. Deformation must therefore be an important consideration in the interpretation of isotopic data because it provides a means of modifying grain size and shape. We illustrate the range of different deformation mechanisms common in micas and use simple models to investigate the relationship between these and isotope diffusion. We consider three different thermal scenarios with deformation taking place during a) the prograde heating path, b) at the closure temperature of the deforming mineral and c) at temperatures significantly below the closure temperature. We have modelled these simple systems using a finite difference algorithm that simulates argon diffusion profiles and bulk ages. This modelling illustrates that obtaining deformation ages is critically dependent on an understanding and recognition of the different deformation mechanisms that have affected the sample. In the cases where deformation causes a change in grain size, it is important to characterise both the temperature at which deformation takes place and the closure temperature of grains formed during the deformation. The development of grains with $T c$ greater than the deformation temperature may record a deformation age. Examples of this condition include i) neocrystallisation; ii) grain size reduction occurring at temperatures below Tc (of the reduced grain size) where the deformation mechanism has reset the grains; and iii) deformationinduced grain coarsening.
\end{abstract}




\section{INTRODUCTION}

The absolute ages of individual deformation events are fundamental to our understanding of the rates of deformation processes and tectonic histories. Radiometric-dating techniques have been employed in attempts to determine absolute ages of deformation (e.g. Kligfield et al. 1986, Kralik et al. 1987, Kelley, 1988, Thoni 1988, Dunlap et al. 1991, Kelley et al. 1994, Freeman et al. 1997, Reddy et al. 1999a). However, in deformed materials, isotope systematics are usually difficult to interpret because isotope migration and the alteration or resetting of isotope systems may be a function of both deformation and temperature. It is our belief that the interpretation of radiometric data as true deformation ages may often be erroneous. This stems from over-simplification of both the microstructural history of the samples (frequently the term 'recrystallisation' is used without any concern for the mechanisms) and the diffusion models employed. In this contribution we discuss the effects that different deformation mechanisms may have on isotope systematics and illustrate some of the implications for radiometric dating using a series of simple case studies. Many geochronologists have already considered the relationship between temperature and grain size and used this to constrain thermal histories of metamorphic rocks. Here, by applying recent advances in our understanding of mica deformation mechanisms and isotope systems, we extend this work to consider cases in which grain size changes as a result of deformation (e.g. Kelley 1988, Goodwin \& Renne 1991, Reddy et al. 1996). Our aim is to illustrate some of the potential complexities associated with dating deformation and provide the structural geologist with a framework within which published 'absolute' deformation ages may be critically assessed.

We restrict our discussion to the ${ }^{40} \mathrm{Ar} /{ }^{39} \mathrm{Ar}$ dating technique. We do this because it is the isotopic system with which we have most experience with regard to deformation studies 
(Kelley et al. 1994, Reddy et al. 1996, Pickles et al. 1997, Reddy et al. 1997, Reddy et al. 1999b). We have placed emphasis on the behaviour of argon in micas. Our reasons for this are that micas are a common K-bearing phase in many deformed crustal rocks; they are widely dated by several isotopic techniques and they appear mineralogically and isotopically less complicated than many other K-bearing phases (e.g. K-feldspar). Micas have the added advantage that as major phases their microstructures can be often related to deformation at the larger scale; something that is difficult to achieve with accessory mineral phases. In addition, the application of ${ }^{40} \mathrm{Ar} /{ }^{39} \mathrm{Ar}$ dating of white mica and biotite to constrain deformation ages has been attempted numerous times (e.g. Kligfield et al. 1986, Wijbrans \& McDougall 1986, Kelley 1988, Dunlap et al. 1991, Goodwin \& Renne 1991, West \& Lux 1993, Kelley et al. 1994, Kirschner et al. 1996, Reddy et al. 1996, Dunlap 1997). Although we restrict our analysis to micas and a specific isotope system, our conclusions are general and will be applicable to other isotopic and mineral systems.

\section{DIFFUSION AND ISOTOPIC AGES}

In the absence of fluid advection, the migration of isotopic species is driven by diffusion. Within individual grains, this is due to concentration gradients within grains and at their boundaries. Diffusion is a strongly temperature-dependent process governed by an Arrhenius relationship. The extent of diffusive equilibration in a mineral is also related to the grain size; the smaller the diffusion distance the shorter the time taken for material to travel from core to rim. Deformation must therefore be an important consideration in the interpretation of isotopic data because it provides a means of changing grain size and therefore affecting isotope systematics.

The relationship between diffusion, temperature and grain size in geological materials was initially developed in terms of the mathematical approximation known as "closure 
temperature" $\left(T_{c}\right)$. The $T_{c}$ of a mineral is defined as its temperature at a time corresponding to its apparent age (Dodson 1973), (Fig. 1), and it relates to a temperature below which significant daughter isotopes accumulate in the mineral. It should be emphasised that $T_{c}$ does not represent the temperature below which there is no diffusion. It is a mathematical simplification that relates the mean age of the age profile across a grain to a temperature in the history of a mineral for a simple cooling system (Dodson 1986), (Fig. 1). In most cases, diffusion below $T_{c}$ will be insignificant. However, in coarse-grained minerals over several millimetres in diameter, diffusion below $T_{c}$ can significantly modify calculated apparent ages because of the scale and magnitude of isotopic diffusion (Reddy et al. 1996). The closure temperature model is based on several significant assumptions, some of which may not be valid in many situations. Of these, isotope migration being dominated by a volume diffusion process ( $c f$. Lee 1995) and the concentration of diffusing species in the grain boundary network being zero ( $c f$. Reddy et al. 1997) are possibly the most significant. Therefore, there are potential problems and pitfalls associated with the application of the closure temperature model. However, we use $T_{c}$ throughout this paper as it represents a useful and readily calculable reference temperature below which the rate of isotope diffusion rapidly decreases.

Closure temperature is controlled by a number of intrinsic parameters and externally controlled variables. Values of $T_{c}$ depend on the diffusion parameters for the isotopic species of concern and the mineral in which diffusion is taking place. Sample cooling rate will affect $T_{c}$ with faster cooling rates yielding higher values for $T_{c}$. Grain size also has a strong control on $T_{c}$ (Dodson 1973, Hames \& Bowring 1994). As deformation has the potential for significantly modifying grain size, deformation processes may significantly change mineral closure temperatures and therefore the isotopic ages we obtain in the laboratory. Furthermore, argon diffusion in micas may be 1000 times greater parallel to (001) planes than perpendicular to them (e.g. Giletti, 1974). As a consequence, argon diffusion in micas is 
normally modelled in terms of cylindrical diffusion geometry (Hames \& Bowring 1994). Therefore when considering the relationship between argon diffusion and deformation in micas it is also necessary to consider whether or not a particular deformation mechanism changes grain size parallel to (001) planes and/or perpendicular to them. These relationships are considered further in the following sections. First we describe how different deformation mechanisms may modify the grain size of micas. Then we assess how these changes may influence the interpretation of argon isotopic ages of white micas in terms of cooling or deformation ages.

DEFORMATION MECHANISMS, GRAIN SIZE AND ISOTOPE DIFFUSION

The deformation of micas has been studied in both naturally deformed samples (Eisbacher, 1970, Etheridge \& Hobbs 1974, Cosgrove 1976, Wilson \& Bell 1979, Bell \& Wilson 1981, Bell \& Rubenach 1983, Behrmann 1984, Lister \& Snoke 1984, Bell et al. 1986, Gibson 1990, Goodwin \& Wenk 1990, Kanaori et al. 1991, Li et al. 1994, Worley et al. 1997) and experimentally (Etheridge \& Hobbs 1974, Meike 1989, Kronenberg et al.1990, Shea \& Kronenberg 1992, Christofferson \& Kronenberg 1993, Mares \& Kronenberg 1993, Shea \& Kronenberg 1993). These studies indicate that mica deformation is often dominated by dislocation glide parallel to (001) and kinking. However, other mechanisms may also occur and these have implications for isotope systematics.

Grain boundary sliding usually takes place at high temperatures and is enhanced by diffusive mass transfer processes. It is usually restricted to fine-grained rocks and is a common deformation mechanism in fault zones (Gibson 1990). Strain may be accommodated with little internal deformation of grains and with no change in grain size (Fig. 2a). Similarly, slip along mica cleavages (Fig. 2b) (Behrmann 1984, Bell \& Wilson 1981, Bell et al. 1986, Wilson \& Bell 1979, Goodwin \& Wenk 1990, Kanaori et al. 1991, Shea \& Kronenberg 
1992,Christofferson \& Kronenberg 1993, Mares \& Kronenberg 1993, Shea \& Kronenberg 1993) and cleavage fracture processes (Fig. 2c) (Behrmann 1984, Lister \& Snoke 1984, Kanaori et al. 1991, Shea \& Kronenberg 1992) may also accommodate strain without a change in effective grain size. Since these deformation mechanisms do not result in a change in effective grain size they do not modify the closure temperature of the grains.

Diffusion-accommodated deformation mechanisms of silicates (Cosgrove 1976, Wilson \& Bell 1979, Lister \& Snoke 1984, Gibson 1990, Li et al. 1994, Worley et al. 1997) may affect grain size in a number of different ways. The diffusion of material in an open system leads to a reduction in grain volume. If, as is the case in mica, the mineral concerned has a non-spherical diffusion geometry for argon (Giletti 1974, Hames and Bowring 1994) then the grain volume may change while the effective grain radius for argon diffusion remains constant (Fig 2d). If removal of mica takes place perpendicular to (001) (Fig. 2e) then the effective grain radius will be reduced and consequently $T_{c}$ will be modified. When diffusive mass transfer takes place within a closed system, grain volumes may remain constant but the sites of dissolution and precipitation in micas will allow both increase (Fig. 2f) and decrease (Fig. 2g) in effective grain size. The sites of dissolution and precipitation will be dependent upon the orientation of the individual grains relative to the stress field. Therefore, it is likely that the effective grain size of the grain for isotopic diffusion will also be orientation dependent for individual grains. The dissolution step of the diffusive mass transfer process may also remove material that had an original radiogenic argon component and replace it with material of no finite age. Therefore, diffusive mass transfer mechanisms have the potential to reset or alter isotope systems.

During the development of so-called 'mica-fish' internal grain boundary migration recrystallisation may occur where the ends of the grain become isolated by the growth of new 
grain boundaries (Fig. 2h) (Eisbacher 1970, Lister \& Snoke 1984, Gibson 1990). As deformation proceeds the new boundaries may migrate inwards reducing the grain size of the porphyroclast still further (Fig. 2h) (Lister \& Snoke 1984). Thus, this form of recrystallisation results in marked grain size reduction and although the ends grow, it is at the expense of the original grain. Similarly, large numbers of small grains may grow around the edges of the porphyroclast (Fig. 2i) (Lister \& Snoke 1984). In such cases, the grain size reduction of the host is not as great but the new grains have much smaller sizes in comparison to grain boundary migration recrystallization (Fig. 2h). These mechanisms are important in isotopic studies because they produce marked changes in grain size and closure temperature. These mechanisms may lead to complete recrystallisation where, the grain almost retains its original shape but the orientation of the (001) planes is changed (Fig. 2j) (Etheridge \& Hobbs 1974, Lister \& Snoke 1984). Although this does not necessarily lead to grain size reduction the recrystallisation process may expel argon and isotopically reset the grain.

Dislocation-accommodated deformation mechanisms may have a complex effect on isotope systematics. At a fundamental level, diffusion of isotopes along dislocations is significantly faster than volume diffusion (Lee \& Aldama 1992, Lee 1995). Dislocation migration through mineral lattices may also sweep along inert gases such that argon migration is related to the migration rate of dislocations and therefore stress and strain rate. These complexities are beyond the scope of this paper and we only consider the results of dislocation-accommodated deformation mechanisms in terms of grain size variations.

Several authors have reported the presence of discontinuities at a high angle to the (001) planes in micas (Fig. 2k). Wilson \& Bell (1979) and Bell \& Wilson (1979) described the segmentation of biotite and, using transmission electron microscopy, Shea \& Kronenberg (1992, 1993) and Christoffersen \& Kronenberg (1993) were able to demonstrate that the pile 
up of dislocations could produce dislocation walls in biotite. Shea \& Kronenberg (1993) also noted that these walls were occasionally fractured and discontinuous fractures have been found in white micas (Bell \& Wilson 1981) and biotite (Wilson \& Bell 1979, Bell \& Wilson 1981). It is difficult to evaluate the effects of these microstructures; they may enhance the diffusion of argon at right angles to the (001) but if the discontinuities terminate within the grain they may have little or no effect. However, if they form a connected network they may reduce the effective grain size by providing fast diffusion pathways (Lee \& Aldama 1992, Lee 1995).

The production of subgrains (Fig. 2l) (Bell \& Wilson 1981) and continued rotation of subgrain walls by the addition of dislocation networks may result in grain size reduction during deformation. However, the extent of subgrain rotation recrystallisation in micas is not well known. Studies of naturally deformed micas have recognised subgrain development in micas at high metamorphic grades (Bell 1979). In contrast, experimental deformation studies have failed to show evidence for dislocation climb as a mechanism in micas (e.g.Kronenberg et al. 1990, Mares \& Kronenberg 1993) but this may simply reflect laboratory conditions. The small number of relatively dispersed subgrains observed in published studies suggests that this deformation mechanism may have little or no significant effect on mica argon ages.

The cataclastic deformation of mica will lead to grain size reduction. However, due to the marked diffusional anisotropy for argon diffusion in white mica, we have drawn a distinction between cleavage fracture processes (Fig. 2c) and fracturing perpendicular or at a high angle to (001) (Fig. 2m). In the latter case the fractures may be the result of crack propagation (Mares \& Kronenberg 1993) or grain boudinage (Wilson \& Bell 1979, Behrmann 1984, Lister \& Snoke 1984) and produce a greatly reduced grain size. Thus, these processes may significantly reduce $T_{\mathrm{c}}$. 
In addition to the above mechanisms, deformation may also lead to the nucleation and crystallisation of new mineral grains. Neocrystallisation of micas during deformation is widely recognised (Bell 1979, Behrmann 1984, Lister \& Snoke 1984) and is an important process in argon dating because such grains should contain no radiogenic isotope component at the time of deformation.

A common but complex microstructure in deformed micas is kinking (Fig 2k) (Etheridge \& Hobbs 1974, Cosgrove 1976, Wilson \& Bell 1979, Bell \& Wilson 1981, Bell \& Rubenach 1983, Lister \& Snoke 1984, Bell et al. 1986, Gibson 1990, Kanaori et al. 1991, Shea \& Kronenberg 1992, Mares \& Kronenberg 1993, Shea and Kronenberg 1993, Li et al. 1994). The maximum grain size in kinked micas will be dependent upon the half-wavelength of the kink structure. However, the minimum grain size associated with kink band boundaries will be controlled by grain boundary migration, diffusive mass transfer, fracture mechanisms and possibly subgrain rotation recrystallisation taking place in the kink band boundary (e.g. Bell et al. 1986). The interactions of this range of mechanisms would be expected to significantly affect argon isotope systematics around kink bands. High spatial resolution argon dating from around such microstructures appear to confirm this (Reddy et al. 1996). In the simplest case, kinking will lead to a general decrease in $T_{c}$ throughout the deformed grains and the distribution of variations in $T_{c}$ will be related to strain variations in the deformed grains. As kinking is directly linked to slip on (001), the formation of kink bands is also strongly orientation dependent. Therefore there is likely to be an orientation dependence on $T_{C}$ and therefore on preserved isotopic ages.

The above discussion outlines some of the characteristics that particular deformation mechanisms possess and in particular illustrates the potential for the different mechanisms to modify grain sizes in deforming micas in different ways. As grain size is an important control 
on $T_{c}$, then it is clear that some deformation mechanisms will have a significant effect on isotope systematics while others will not. However, the significance of the different deformation mechanisms will be dependent upon the temperature at which the deformation takes place, the closure temperature of the original grains and the modification of the closure temperature by the deformation process. The effects of these factors are discussed in the following section.

\section{RELATIONSHIPS OF DEFORMATION, DIFFUSION AND THERMAL HISTORY}

In this section, we discuss the potential importance of deformation - isotope diffusion relationships by considering the timing of deformation in relation to the thermal history of a set of model samples. In these models we only consider volume diffusion in white mica (diffusion parameters from Hames \& Bowring (1994)). In all cases, we have assumed a predeformational grain radius of $1 \mathrm{~mm}$ and, where relevant, a grain radius reduction to $0.1 \mathrm{~mm}$. The effects of grain coarsening are also described qualitatively based on these results. Throughout we assume a $10^{\circ} \mathrm{C} / \mathrm{Ma}$ cooling rate. These values yield $T_{c}$ of $445^{\circ} \mathrm{C}$ and $368^{\circ} \mathrm{C}$ for $1 \mathrm{~mm}$ and $0.1 \mathrm{~mm}$ grains respectively. We discuss a very simple system comprising a metamorphic event in which three deformation events have taken place. The three events $\left(D_{1}\right.$, $D_{2} \& D_{3}$ ) represent short-lived periods of deformation that occurred at the following times; 1 ) during the prograde temperature-time $(T-t)$ path $\left.\left(450^{\circ} \mathrm{C}\right), 2\right)$ around $T_{C}$ during cooling $\left(445^{\circ} \mathrm{C}\right)$ and 3) at temperatures significantly below $T_{c}$ for the $1 \mathrm{~mm}$ grains $\left(395^{\circ}\right)$ (Fig.3). In the case of $\mathrm{D}_{1}$, we have modelled a $10{ }^{\circ} \mathrm{C} / \mathrm{Ma}$ heating rate up to the metamorphic peak at $500{ }^{\circ} \mathrm{C}$ and the metamorphic peak temperature was maintained for 5 Ma before the commencement of cooling. We first consider deformations that have no effect on the grain size of white micas in the sample. Later, we use these results to consider the effects of progressively more complicated cases with deformation-induced, grain size changes. We have modelled these 
simple systems using a finite difference algorithm that simulates argon diffusion profiles and bulk ages (the DIFFARG program of Wheeler (1996)).

\section{Deformation with no change in grain size}

In this simple case, deformation of the rock is modelled assuming that deformation does not result in a change in grain size. We do not necessarily believe that such simple cases commonly occur in nature. However, the examples illustrate some of the complexities that arise even in the simplest systems. The deformation mechanisms being modelled include those in which there is no internal deformation (e.g. grain boundary sliding, Fig. 2a) and those in which intragrain deformation does take place (e.g. cleavage slip, cleavage fracture and diffusional mass transfer perpendicular to (001) (Fig. 2b, c \& d)).

In our first example, the effect of the post-deformational thermal history has been modelled following the $\mathrm{D}_{1}$ deformation. The spatial distribution of radiogenic argon in the grain is shown in Fig. 4a (i), the apparent or spatially averaged age across a single grain is shown in Fig. 4a (ii) and the temperature time path after deformation (at $t=0$ ) is shown in Fig. 4a (iii). Since the deformation does not modify the effective grain size, the final distribution of ages would be the same as if the grains had not undergone the deformation event. The final age recorded by the sample, $30 \mathrm{Ma}$ after the deformation event, is $15 \mathrm{Ma}$. This age corresponds (within $0.5 \mathrm{Ma}$ ) to the time at which the rock passed through the $445^{\circ} \mathrm{C}$ closure temperature on the retrograde side of the $T$ - $t$ path. Thus there is no record of the deformation event preserved in the grains because the temperature was sufficiently high that radiogenic argon was lost from the sample. However, an interesting feature highlighted by the modelling (Fig 4a (i-iii)) is that at the metamorphic peak $\left(c .50^{\circ} \mathrm{C}\right.$ above the closure 
temperature), the grain still has a finite age (c. $1 \mathrm{Ma}$ ) due to the mismatch in the relative rates of radiogenic argon production and loss by diffusion.

For $\mathrm{D}_{2}$, deformation takes place at $T_{c}$. However, because there is no change in grain size (Fig.2a) or effective grain size (Fig $2 \mathrm{~b} \& \mathrm{c}$ ) the final age will be identical to that above and the grain will yield a cooling age. Coincidentally in the case of $\mathrm{D}_{2}$, the final age is within $1 \mathrm{Ma}$ of the deformation age but this is simply because we have chosen to look at deformation taking place at $T_{c}$. The same cooling age is observed for deformation at $\mathrm{D}_{3}$. Consequently, for the case in which there is no change in grain size and no resetting of isotope systems by the active deformation mechanisms, no deformation age can be obtained.

\section{Deformation-Induced Neocrystallisation}

In our next example, we assume that deformation is associated with neocrystallisation and that these new grains have a final grain radius of $1 \mathrm{~mm}$. In the case of $\mathrm{D}_{1}$, our results are identical to a previous example and the final age will be a cooling age. In the case of $\mathrm{D}_{2}$, the new grains grown at their closure temperature will undergo the loss of some radiogenic argon component during the early stages of cooling. Modelling (not shown here) shows the difference between the real deformation age and the apparent grain ages to be of the order of $1 \mathrm{Ma}$. The exact figure has a grain size dependence and would change if we were to consider growing different size new grains at a different temperature (but still at their closure temperature). In the case of $\mathrm{D}_{3}$, where deformation and grain growth has occurred $50^{\circ} \mathrm{C}$ below $T_{c}$ (Fig. 4b), only the outermost $0.2 \mathrm{~mm}$ of the grain undergoes any argon loss after the deformation event (Fig. 4b (i)). The final age is a close approximation to the age of deformation (Fig. 4b (ii)). In this scenario of new grain growth, it is important to emphasise that an age approaching the deformation age will only be obtained when deformation (i.e. 
neocrystallisation) occurs below the closure temperature of the grains that are growing during the deformation. Furthermore, the magnitude of the discrepancy between the deformation age and the apparent age (Fig $4 \mathrm{~b}$ (ii)) will be controlled by the difference between $T_{c}$ and the temperature at which the deformation takes place.

The above models of neocrystallisation are clearly an oversimplification. Dynamic crystallisation of new mica grains is likely to produce a range of grain sizes that may be contaminated by relict pre-deformational micas of a different age. However, careful analysis of mica microstructure and grain size distributions prior to argon analysis may allow these complications to be accounted for. This has recently been illustrated by an excellent and detailed study of neocrystallisation of white mica during deformation by Dunlap (1997).

\section{Deformation associated with a change in grain size}

Again, we consider three deformation events taking place at different parts of the $T-t$ path (Fig. 3) but now we consider the effects of grain size changes during deformation. We have modelled the effects of grain radius reduction from $1 \mathrm{~mm}$ to $0.1 \mathrm{~mm}$. As outlined earlier both plastic and brittle deformation mechanisms can lead to grain size reduction. However we can distinguish two different scenarios; firstly deformation in which the mechanism itself does not give rise to isotopic re-equilibration (e.g. cataclasis, Fig 2l) and secondly mechanisms in which the isotope systematics are reset (e.g. dynamic recrystallisation processes such as grain boundary migration recrystallisation).

For the case of a prograde deformation event $\left(D_{1}\right)$ with a temperature significantly below the thermal peak, both types of mechanism will result in cooling ages. The final age of the sample will date the time at which the sample passes through the closure temperature of 
the reduced grain size $\left(368^{\circ} \mathrm{C}\right)$ not the original grain size (Fig 4c (i-iii)). All of the radiogenic argon produced within the grain is lost by diffusion during the metamorphic peak and the start of argon accumulation takes place $15 \mathrm{Ma}$ after the deformation event. This contrasts the earlier prograde example (Fig 4a) where the rate of argon diffusion across the larger grain was sufficiently slow to preserve a small apparent age in the core of the grain. The reduction in grain size in this example changes the time of closure, compared to the $1 \mathrm{~mm}$ grain of Fig. 4a, by c. 8 Ma. The discrepancy between the deformation age and the argon age would be $c$. $23 \mathrm{Ma}$.

For deformation around the original closure temperature of the $1 \mathrm{~mm}$ grains $\left(\mathrm{D}_{2}\right)$, the decrease in grain size significantly reduces $T_{c}$ and opens all of the grains to isotopic diffusion. Analysis of deformed white micas will again yield cooling ages that correspond to the closure temperature for the $0.1 \mathrm{~mm}$ grains.

For $\mathrm{D}_{3}$, the interpretation of whether the reduced grains yield deformation or cooling ages will depend upon the temperature of the deformation and $T_{c}$ of the deformed grains. If the temperature of deformation is higher than $T_{c}$ for the $0.1 \mathrm{~mm}$ grains $\left(368^{\circ} \mathrm{C}\right)$, the grains will be reset and will record a cooling age. If $T_{c}$ of the $0.1 \mathrm{~mm}$ grains $\left(368^{\circ} \mathrm{C}\right)$ is significantly higher than the temperature during deformation then there is a further complication. We must consider whether the deformation mechanism producing the grain size reduction isotopically resets the grain or not. In the case where $T_{c}$ of the $0.1 \mathrm{~mm}$ grains is higher than the temperature of deformation and deformation mechanisms reset the grains isotopically then the measured age will be a deformation age. Where the deformation mechanism does not reset the grain, the radiogenic argon accumulated between original closure of the $1 \mathrm{~mm}$ grain and the time of deformation will contribute to the measured age. The measured age will also contain an argon 
component derived radiogenically since the deformation. Thus, the age will be a mixing age that is older than the true deformation age.

The above examples consider an extremely simple model of grain size reduction. In nature, mixed populations of porphyroclast and recrystallised grains are commonly found (Lister \& Snoke 1984). In such a case (e.g. Fig. 2h) there would be at least two different values for $T_{c}$ in the same original grain. The reduced grain size at the edge of the original grain would be expected to have lower values of $T_{c}$ than the porphyroclast core and the cores would be expected to have a lower $T_{c}$ than the original grain. If we consider this model at $\mathrm{D}_{2}$, that is at the closure temperature of the original $1 \mathrm{~mm}$ grain, then the porphyroclast cores and the recrystallised grains would have a closure temperature below the temperature of $\mathrm{D}_{2}$ deformation. The range of grain sizes preserved in different porphyroclastic cores and recrystallised grains would therefore potentially record a range of cooling ages. This can have advantages. For example, Reddy et al (1996) illustrated an example of heterogeneous grain size reduction (in biotite) at deformation temperatures significantly above the closure temperature for the observed grain sizes (equivalent to model $\mathrm{D}_{1}$ or $\mathrm{D}_{2}$ ). Although estimates of the age of deformation responsible for the reduction are precluded by this relationship, analysis of different grain sizes yielded important constraints on the post-metamorphic thermal history of the sample. By comparison with the previously discussed models, more complex scenarios can be envisaged in which the range of grain sizes produced during deformation have a range of closure temperatures that vary in such a way with the temperature of deformation that some grains yield cooling ages while others date the deformation.

As well as producing grain size reduction, deformation may cause grain coarsening. Deformation mechanisms such as closed-system diffusive mass transfer (Fig. 2f) may lead to 
increased grain or effective grain radii and therefore an increase in closure temperatures. In some cases, grain coarsening may increase the closure temperature of the mineral to temperatures in excess of the deformation temperature. In this situation, the deformed grains pass from isotopically open to closed systems and will therefore record deformation ages. In the simple thermal model described above, if recrystallised grains are sufficiently coarse that their $T_{c}$ are greater than the temperature of $\mathrm{D}_{1}$, the peak temperature and the deformation temperatures of $\mathrm{D}_{2}$ and $\mathrm{D}_{3}$, it would be theoretically possible to obtain deformation ages for all three deformation events. Grain coarsening during deformation is therefore a potentially powerful tool for dating deformation.

\section{APPLICATION OF ${ }^{40} \mathrm{Ar} /{ }^{39} \mathrm{Ar}$ TECHNIQUES TO DATING DEFORMATION}

The above discussion outlines some of the general issues regarding the interpretation of deformation ages. In this section, we specifically discuss the ${ }^{40} \mathrm{Ar} /{ }^{39} \mathrm{Ar}$ dating technique and in particular illustrate some of the potential problems of applying the technique to the dating of deformation. We have outlined in the previous sections that to correctly interpret deformation ages a detailed microstructural description of the sample is required. This description should include accurate grain sizes and evidence of the operation of deformation mechanisms and inferences concerning grain size changes if they have occurred. This data must then be used to calculate predicted closure temperatures and these in turn compared to the temperature during deformation. To calculate $T_{c}$, the cooling rate and the diffusion parameters for the system are required. Cooling rates in metamorphic rocks are usually obtained by calculating the closure temperatures of a range of different minerals by a range of different isotope techniques - a somewhat circular argument. Alternative approaches that establish the T-t history of a sample by modelling K-feldspar Ar data and then use this to constrain the significance of white mica ages (e.g. Dunlap 1997) are useful. However, the 
application of K-feldspar modelling to deformed K-feldspar has its own problems (Reddy et al 1999b). A further complication is that the diffusion parameters for argon diffusion in muscovite are not well known. Consequently, the estimates of $T_{c}$ for a particular grain size and cooling rate may be erroneous depending upon which set of preferred parameters are used in the calculation. Indeed, as clearly illustrated by Dunlap (1997), application of incorrect diffusion parameters can lead to completely different interpretations of isotopic data. The likely errors in $T_{c}$ due to incorrect selection of both cooling rate and diffusion parameters are indicated in figure 5. Clearly, for a particular grain size, estimates of $T_{C}$ may vary considerably. However, as discussed earlier using a correct $T_{c}$ is paramount to the correct interpretation of deformation ages. There is therefore an urgent need for further research to better constrain these diffusion parameters.

\section{CONCLUSIONS}

The temperature control on diffusion is strongly linked to grain size and therefore processes that may modify grain size may modify isotope systematics. A range of deformation mechanisms may take place in micas. These have different implications for grain size modification and the resetting of isotope systems during deformation. To utilise the relationship between deformation and isotope diffusion and interpret deformation ages requires a full understanding of the potential interactions of these mechanisms and the thermal history of the sample. For argon diffusion in micas, diffusional anisotropy suggests there will also be a relationship between grain orientation and age. Our results from simple modelling illustrate that in deforming rocks in which there is no change in grain size, it is difficult to get true deformation ages. In the cases where deformation causes a change in grain size, it is important to characterise the temperature of deformation and the closure temperature of grains formed during the deformation. Without this information, distinction between cooling 
and deformation ages is equivocal. The development of grains with $T_{c}$ greater than the temperature during deformation will record a deformation age. This situation may arise in the following cases; i) neocrystallisation, ii) when grain size reduction occurs at temperatures below $T_{c}$ of the reduced grain size and the deformation mechanism has reset the grains; iii) when deformation-induced grain coarsening has occurred. Since closure temperatures are also dependent upon cooling rate and diffusion parameters, these must also be known for a correct interpretation of the radiometric data.

Acknowledgements - P. Huddleston, M. Markley and J. Evans are thanked for reviewing this manuscript and K. Lancaster is thanked for drawing and patiently changing figure 2 as we repeatedly changed our minds. This paper is Tectonics Special Research Centre Publication No. 40.

\section{References}

Behrmann, J. H. 1984. A study of white mica microstructure and microchemistry in a low grade mylonite. Journal of Structural Geology 6, 283-292.

Bell, I. A. \& Wilson, C. J. L. 1981. Deformation of biotite and muscovite: TEM micrsotructure and deformation model. Tectonophysics 78, 201-228.

Bell, I. A., Wilson, C. J. L., McLaren, A. C. \& Etheridge, M. A. 1986. Kinks in mica: Role of dislocations and (001) cleavage. Tectonophysics 127, 49-65.

Bell, T. H. 1979. The deformation and recrystallisation of biotite in the Woodroffe Thrust Mylonite Zone. Tectonophysics 58, 139-158. 
Bell, T. H. \& Rubenach, M. J. 1983. Sequential porphyroblast growth and crenulation cleavage development during progressive deformation. Tectonophysics 92, 171-194.

Christofferson, R. \& Kronenberg, A. K. 1993. Dislocation interactions in experimentally deformed biotite. Jurnal of Structural Geology 15(9/10), 1077-1095.

Cosgrove, J. W. 1976. The formation of crenulation cleavage. Journal of the Geological Society of London 132, 155-178.

Dodson, M. H. 1973. Closure temperature in cooling geochronological and petrological systems. Contributions to Mineralogy and Petrology 40, 259-274.

Dodson, M. H. 1986. Closure profiles in cooling systems. Materials Science Forum 7, 145153.

Dunlap, W. J. 1997. Neocrystallisation or cooling? ${ }^{40} \mathrm{Ar} /{ }^{39} \mathrm{Ar}$ ages of white micas from lowgrade mylonites. Chemical Geology 143, 181-203.

Dunlap, W. J., Teyssier, C., McDougall, I. \& Baldwin, S. 1991. Ages of deformation from ${ }^{40} \mathrm{Ar} /{ }^{39} \mathrm{Ar}$ dating of white micas. Geology 19, 1213-1216.

Eisbacher, G. H. 1970. Deformation mechanics of mylonitic rocks and fractured granites in Cobequid Mountains, Nova Scotia, Canada. Geological Society of America Bulletin 81, 2009-2020.

Etheridge, M. A. \& Hobbs, B. E. 1974. Chemical and deformational controls on recrystallization of mica. Contributions to Mineralogy and Petrology 43, 111-124. 
Freeman, S. R., Inger, S., Butler, R. W. H. \& Cliff, R. A. 1997. Dating deformation using RbSr in white mica: Greenschist facies deformation ages from the Entrelor shear zone, Italian Alps. Tectonics 16, 57-76.

Gibson, R. G. 1990. Nucleation and growth of retrograde shear zones: an example from the Needle Mountains, Colorado, USA. Journal of Structural Geology 12, 339-350.

Giletti, B. J. 1974. Studies in diffusion, I. Argon in phlogopite mica. In: Geochemical Transport and Kinetics (edited by Hofmann, A. W., Giletti, B. J., Yoder, H. S. \& Yund, R. A.). Carnegie Institution of Washington, Washington, D.C., 107-115.

Goodwin, L. B. \& Renne, P. R. 1991. Effects of progressive mylonitization on Ar retention in biotites from the Santa Rosa mylonite zone, California, and thermochronologic implications. Contributions to Mineralogy and Petrology 108, 283-297.

Goodwin, L. B. \& Wenk, H.-R. 1990. Intracrystalline folding and cataclasis in biotite of the Santa Rosa mylonite zone: HVEM and TEM observations. Tectonophysics 172, 201214.

Hames, W. E. \& Bowring, S. A. 1994. An empirical evaluation of the argon diffusion geometry in muscovite. Earth and Planetary Science Letters 124, 161-167.

Kanaori, Y., Kawakami, S.-I. \& Yairi, K. 1991. Microstructure of deformed biotite defining foliation in cataclasite zones in granite, central Japan. Journal of Structural Geology 13, 777-785. 
Kelley, S. P. 1988. The relationship between K-Ar mineral ages, mica grain sizes and movement on the Moine Thrust Zone, NW Highlands, Scotland. Journal of the Geological Society of London 145, 1-10.

Kelley, S. P., Reddy, S. M. \& Maddock, R. 1994. Laser-probe ${ }^{40} \mathrm{Ar} /{ }^{39} \mathrm{Ar}$ investigation of a pseudotachylyte and its host rock from the Outer Isles thrust, Scotland. Geology 22, 443-446.

Kirschner, D. L., Cosca, M. A., Masson, H. \& Hunziker, J. C. 1996. Staircase ${ }^{40} \mathrm{Ar} /{ }^{39} \mathrm{Ar}$ spectra of fine-grained white mica - Timing and duration of deformation and empirical constraints on argon diffusion. Geology 24, 747-750.

Kligfield, R., Hunziker, J., Dallmeyer, R. D. \& Schamel, S. 1986. Dating of deformation phases using K-Ar and ${ }^{40} \mathrm{Ar} /{ }^{39} \mathrm{Ar}$ techniques: results from the Northern Apennines. Journal of Structural Geology 8, 781-798.

Kralik, M., Klima, K. \& Riedmüller, G. 1987. Dating fault gouges. Nature 327, 315-317.

Kronenberg, A. K., Kirby, S. H. \& Pinkston, J. 1990. Basal slip and mechanical anisotropy of biotite. Journal of Geophysical Research 95, 19257-19278.

Lee, J. K. W. 1995. Multipath diffusion in geochronology. Contributions to Mineralogy and Petrology 120, 60-82.

Lee, J. K. W. \& Aldama, A. A. 1992. Multipath diffusion: A general numerical model. Computers and Geosciences 5, 531-555. 
Li, G., Peacor, D. R., Merriman, R. J., Roberts, B. \& van der Pluijm, B. A. 1994. TEM and AEM constraints on the origin and significance of chlorite - mica stacks in slates: an example from Central Wales, U.K. Journal of Structural Geology 16, 1139-1157.

Lister, G. S. \& Snoke, A. W. 1984. S-C mylonites. Journal of Structural Geology 6, 617-638.

Mares, V. M. \& Kronenberg, A. K. 1993. Experimental deformation of muscovite. Journal of Structural Geology 15, 1061-1075.

Meike, A. 1989. In situ deformation of micas: a high-voltage electron-microscope study. American Mineralogist 74, 780-796.

Pickles, C. S., Kelley, S. P., Reddy, S. M. \& Wheeler, J. 1997. Determinations of high spatial resolution argon isotope variations in metamorphic biotites. Geochemica Cosmochimica et Acta 61, 3809-3824.

Reddy, S. M., Kelley, S. P. \& Wheeler, J. 1996. A ${ }^{40} \mathrm{Ar} /{ }^{39} \mathrm{Ar}$ laserprobe study of rocks from the Sesia Zone: Excess argon, argon loss and implications for metamorphic and deformation histories. Journal of Metamorphic Geology 14, 493-508.

Reddy, S. M., Kelley, S. P. \& Magennis, L. 1997. A microstructural and argon laserprobe study of shear zone development on the western margin of the Nanga Parbat Syntaxis, north Pakistan. Contributions to Mineralogy and Petrology 128, 16-29.

Reddy, S. M., Wheeler, J. \& Cliff, R. A. 1999a. The geometry and timing of orogenic extension: An example from the western Italian Alps. Journal of Metamorphic Petrology (in press). 
Reddy, S. M., Potts, G. J. \& Kelley, S. P. 1999b. The effects of deformation-induced microstructures on intragrain argon isotope ages in K-feldspar. Geology (in press).

Robbins, G.A., 1972. Radiogenic argon diffusion in muscovite under hydrothermal conditions. M. S. Thesis, Brown University, 1972.

Shea, W. T. \& Kronenberg, A. K. 1992. Rheology and deformation mechanisms of an isotropic mica schist. Journal of Geophysical Research 97, 15201-15237.

Shea, W. T. \& Kronenberg, A. K. 1993. Strength and anisotropy of foliated rocks with varied mica contents. Journal of Structural Geology 15, 1097-1121.

Thoni, M. 1988. Rb-Sr isotopic resetting in mylonites and pseudotachylites: Implications for the detachment and thrusting of the Austroalpine basement nappes in the Eastern Alps. Jahrbuch der Geologischen Bundesanstalt Wein 131, 169-201.

West, D. P. J. \& Lux, D. R. 1993. Dating mylonitic deformation by the ${ }^{40} \mathrm{Ar}^{-}{ }^{39}$ Ar method: An example from the Norumbega Fault Zone, Maine. Earth and Planetary Science Letters 120, 221-237.

Wheeler, J. 1996. DIFFARG: A program for simulating argon diffusion profiles in minerals. Computers \& Geosciences 22, 919-929.

Wijbrans, J. R. \& McDougall, I. 1986. 40Ar/39Ar dating of white micas from an Alpine highpressure metamorphic belt on Naxos (Greece) - the resetting of the argon isotopic system. Contributions to Mineralogy and Petrology 93, 187-194. 
Wilson, C. J. L. \& Bell, I. A. 1979. Deformation of biotite and muscovite: Optical microstructure. Tectonophysics 58, 179-200.

Worley, B., Powell, R. \& Wilson, C. J. L. 1997. Crenulation cleavage formation: Evolving diffusion, deformation and equilibration mechanisms with increasing metamorphic grade. Journal of Structural Geology 19, 1121-1135. 


\section{Figure Captions}

Fig. 1 (a) Temperature ( $T$ )-time ( $t$ ) path for a simple cooling system. (b) Change in daughter/parent $(\mathrm{D} / P)$ ratio of a radiogenic isotopic system as a function of time. Together parts (a) and (b) illustrate the relationship between apparent age $\left(t_{c}\right)$ and closure temperature ( $\left.T_{c}\right)$ (after Dodson 1973). (c) Schematic diagram of the distribution of apparent ages in an individual grain of radius a (after Dodson 1986). The age profile arises from the diffusion of argon from the grain. The dotted line represents the spatially averaged age of the grain, which is equivalent to $t_{c}$ in part (b).

Fig. 2. Conceptual models of grain-scale deformation mechanisms in micas. (a) Grain boundary sliding. (b) Sliding on basal (001) planes with or without fracture. (c) Cleavage fracture along basal planes. Although grain size is reduced, the higher diffusion rate parallel to (001) ensures that the effective grain size is unchanged by mechanisms (b) and (c). (d) Diffusive mass transfer in an open system that leads to a reduction in grain volume. Dissolution parallel to (001) does not significantly change the effective grain size for argon diffusion. (e) Diffusive mass transfer in an open system. Dissolution perpendicular to the basal planes may significantly reduce the effective grain size. (f)-(g) Diffusive mass transfer in a closed system produces changes in effective grain size of relict grains (as described in (d) and (e)). Overgrowths will consist of new material that did not possess radiogenic argon at the time of growth. In (f) the overgrowths increase the effective grain size but in (g) they have little or no effect. (h) Internal grain boundary migration recrystallisation. The new grain boundaries grow at a high angle to the (001) planes of the host. (i) Grain boundary migration recrystallisation. In this case new small grains are formed at the margins of the porphyroclast. (j) Grain boundary recrystallisation may result in complete recrstallisation where, although 
the grain may not significantly change size (and shape) the recrystallisation process may change the effective grain size (parallel to (001)) and expel argon from the grain. (k) Discontinuities at high angles to (001) planes in micas. The discontinuities may be dislocation walls, fractures or a combination of both. (l) Subgrains in micas. These are not common and appear to be dispersed throughout the grains unlike more familiar microstructures in quartz. (m) Fracture perpendicular or at moderate angles to (001) planes. (n) Kinking. The axial surfaces of the kinks may behave as grain boundaries and thus, the grain size is reduced. Note that recrystallisation of new small grains may occur along the (highly deformed) kink band axial surfaces.

Fig3. Illustration of the relationship between thermal history and deformation events used to investigate the association between deformation mechanisms and argon diffusion.

Fig. 4. Selection of diffusion models used to investigate the relationships between deformation and argon isotope systematics with temperature and time. In cases a-d the three graphs (i-iii) illustrate the relationship between apparent argon ages across the grain (i) and how the bulk age of the grain evolves with time (ii). Lines in (i) correspond to the crosses marked on the age-time line (ii) and temperature-time path (iii). In each individual case (a-d) deformation took place at $t=0$. The time axes in (ii) and (iii) therefore mark the true time since deformation. The discrepancy between the true age and the obtained argon age is given by the difference in this age and the apparent ages shown in (i) and (ii). (a) Argon distribution for a $1 \mathrm{~mm}$ grain deformed at $\mathrm{D}_{1}$ on the prograde part of the T-t curve. (b) Argon distribution for a $1 \mathrm{~mm}$ newly crystallised grain that grew during $\mathrm{D}_{3}$. (c) Argon distribution for a grain, reduced by deformation to $0.1 \mathrm{~mm}$ during $\mathrm{D}_{1}$. Comparison with (a) illustrates the effect of a reduced $T_{c}$. (d) Effect of grain size reduction and isotopic resetting during deformation at $\mathrm{D}_{2}$ 
(at $T_{c}$ of the original $1 \mathrm{~mm}$ grains $\left(445^{\circ}\right)$ ). The final age is a cooling age recording passage through $c .368^{\circ} \mathrm{C}$. See text for details.

Fig 5. Illustration of the variation of closure temperature as a function of grain radius for (a) different cooling rates and (b) different diffusion parameters. Detailed microstructural studies may yield well- constrained values for grain radius but large errors in $T_{c}$ may arise from incorrect selection of cooling rate and diffusion parameters. 
Figure 1. Reddy and Potts

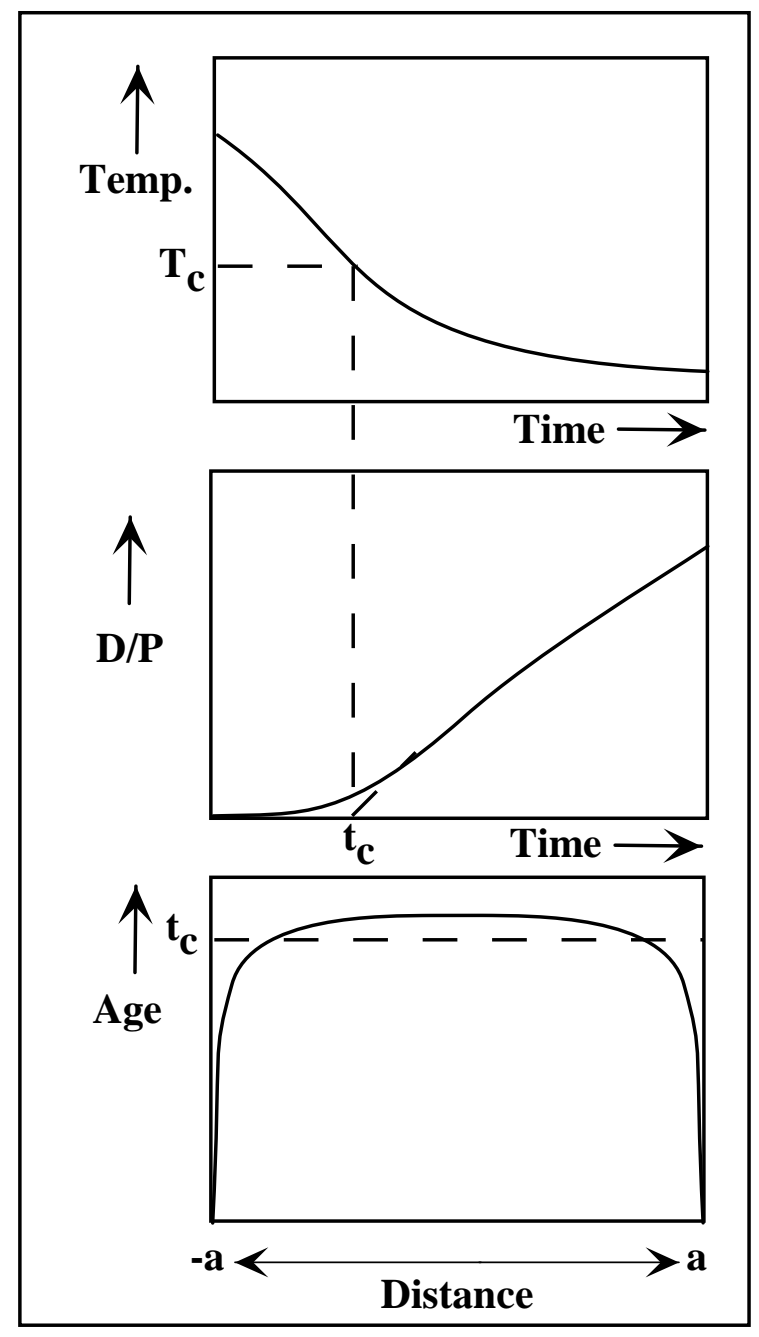


Figure 2. Reddy and Potts

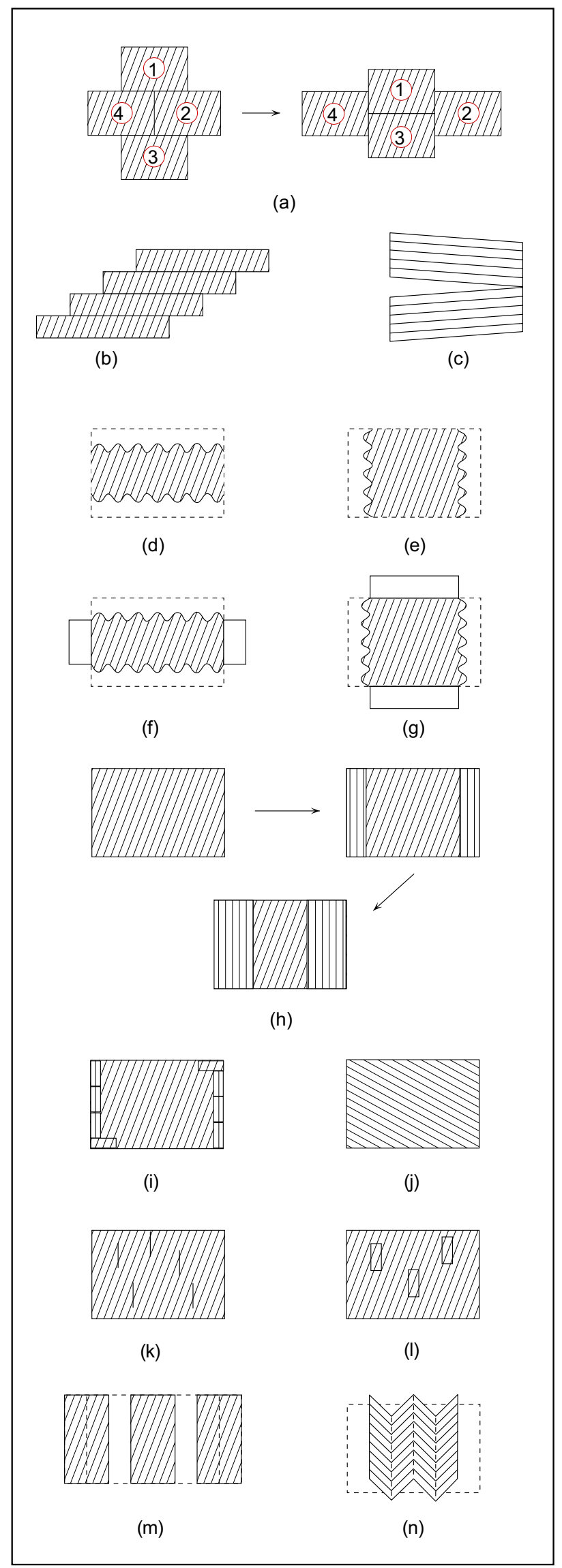




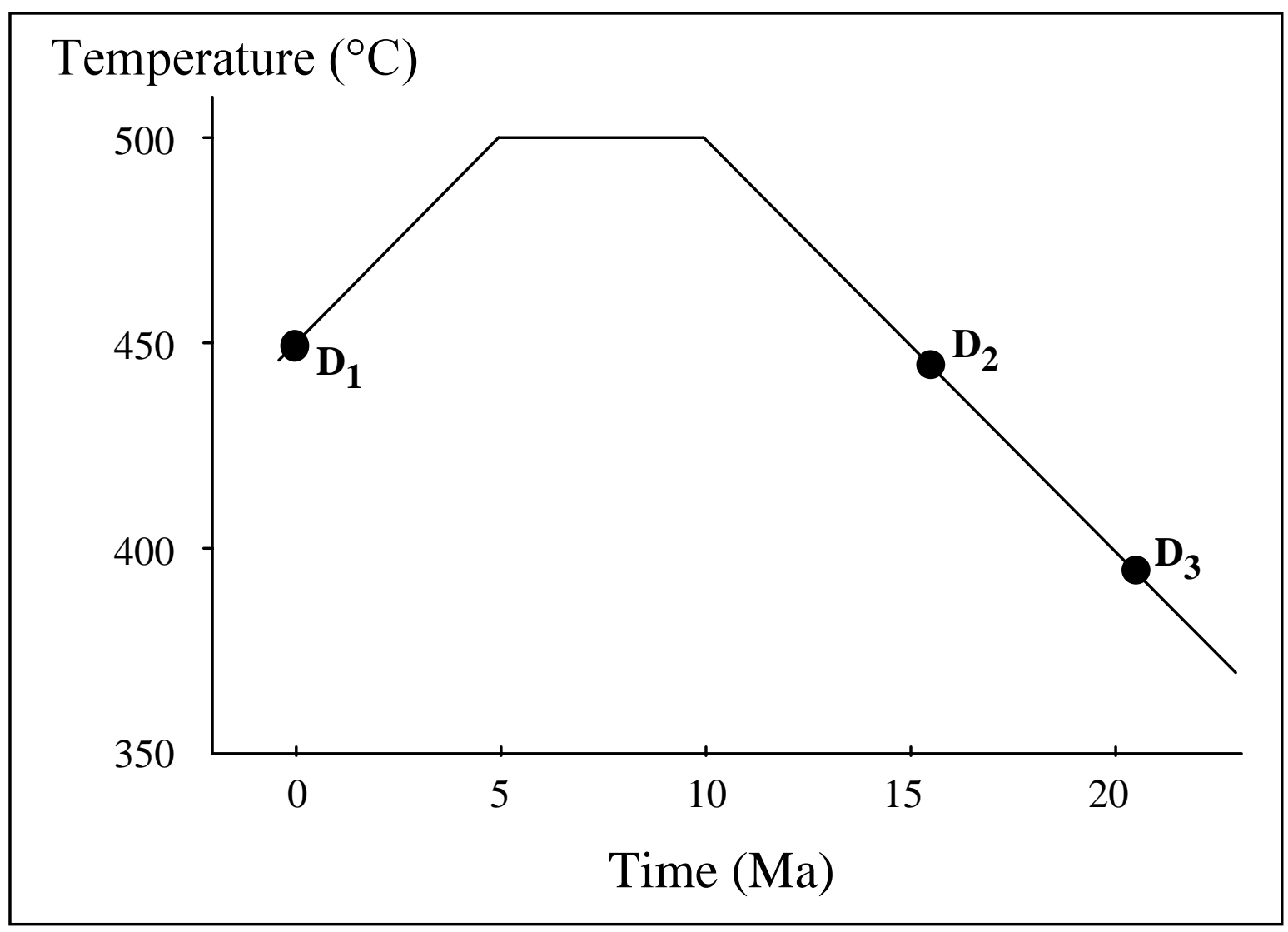




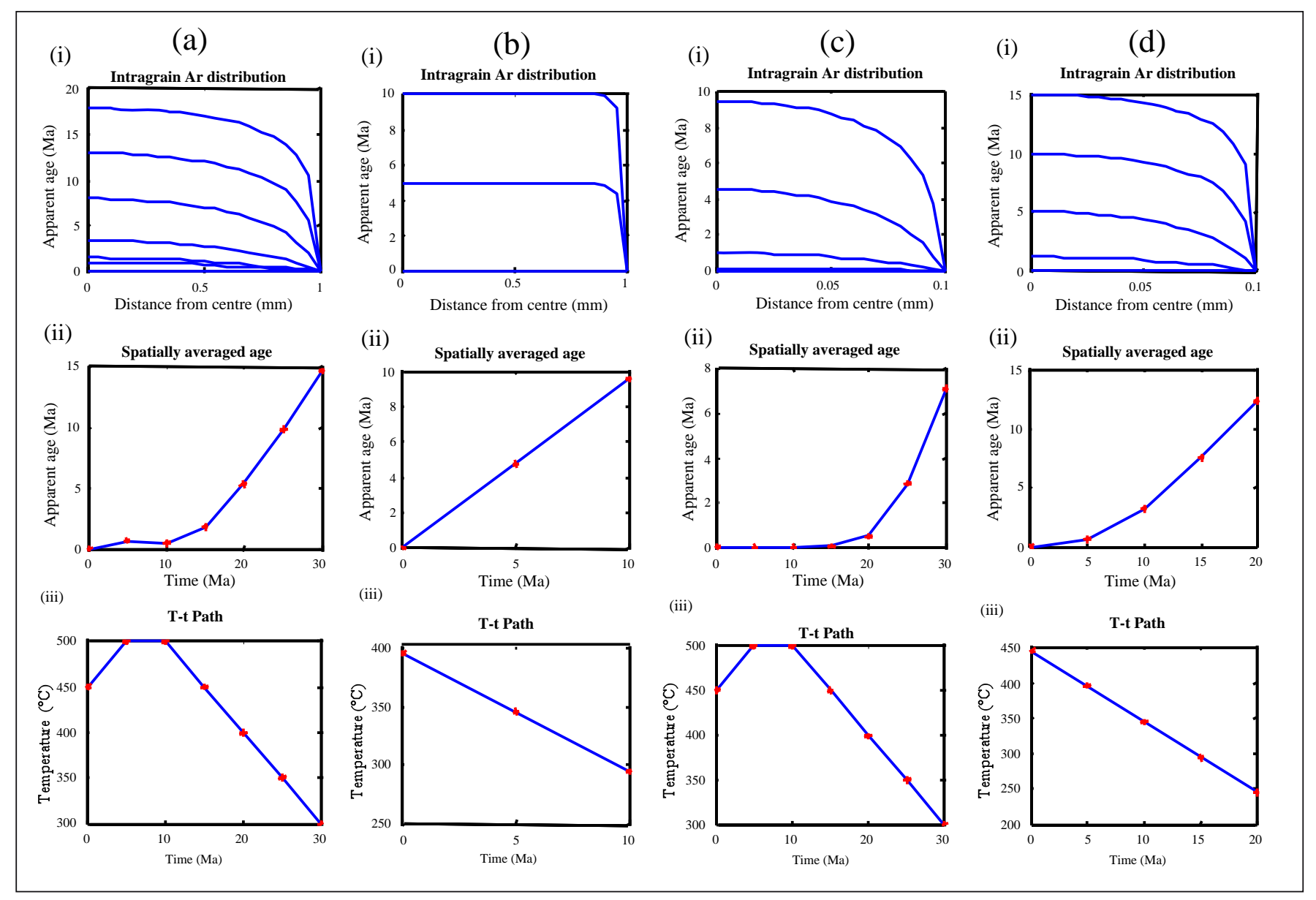



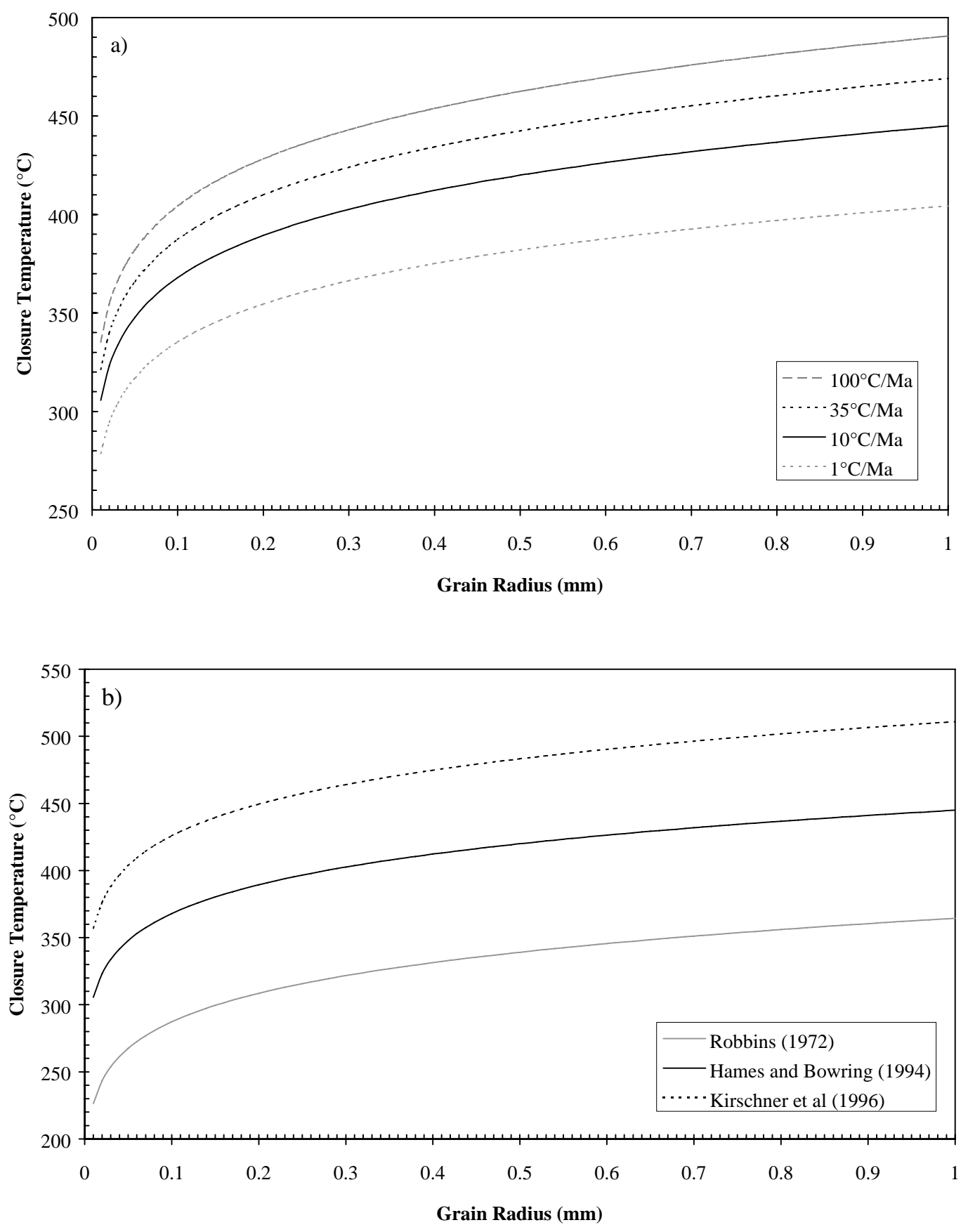